\title{
The 'policy-preferences model': a new perspective on how researchers can facilitate the take-up of evidence by educational policy makers
}

\begin{abstract}
Chris Brown
The phrase 'knowledge adoption' refers to the often-complicated process by which policy makers 'take on board' evidence. While models have been put forward to explain this activity, this paper argues that such models are flawed and fail to fully address those complexities affecting the successful realisation of knowledge adoption efforts. Existing frameworks are examined, critiqued and an alternative, sociologically based approach presented. It is argued that this alternative conceptualisation provides a more effective account of the knowledge adoption process. The paper illustrates how this model has been tested and examines its implications for both research impact and evidence-informed policy making.
\end{abstract}

\section{Introduction}

The realisation of evidence-informed policy making is, in part, dependent on what is known as 'knowledge adoption': the process, in all its complexity, of policy makers digesting, accepting and then 'taking on board' research findings; noting their relevance, benefits or future potential (Brown, 2012a, 2012b). Present thinking as to how the knowledge adoption process might be explained or undertaken most effectively is expressed in a number of extant models. This paper argues, however, that these models fail to address a number of issues that are central to any fundamental conceptualisation of knowledge adoption or to its successful realisation. For example, that:

- individually, such models fail to capture fully the complexities of the knowledge adoption process;

- there is no satisfactory overarching theory that accounts effectively for the process of research adoption and how it might be improved;

- existing models fail to reflect the social nature of knowledge adoption or the motivations of social actors to engage in such activity;

- the models proposed to date do not differentiate between the varying contexts that researchers may find themselves in. 
The aims of this paper, therefore, are to:

- describe existing models of knowledge adoption and demonstrate how such models have been substantially critiqued;

- illustrate how this critique has instigated the development of a new model of knowledge adoption based in extant sociological theory;

- show how this model was derived from a systematic review of existing literature and how it was empirically tested;

- illustrate the implications of the model for the notions of research impact and of evidence-informed policy making more widely.

This paper stems from a project undertaken between 2009 and 2011. Its focus was (a) to review existing conceptualisations of knowledge adoption and, in particular, to examine explanatory models of how evidence feeds into the policy-making process (specifically with regard to the education sector in England and Wales) and (b) to put forward suggestions for how knowledge adoption processes might be effectively implemented by researchers, with a view to increasing the use of evidence within policy making.

\section{Methodology: the literature review}

The first part of this paper comprises a literature review. The aim of the review was to provide an overview of existing theory and an understanding of the type of empirical studies previously undertaken in this area. While systematic in approach, the review did not replicate all of the steps that systematic reviews employ: this was because the primary requirement of the review was for it to provide general understanding, rather than a comprehensive assessment of empirical evidence. This corresponds with a configurative rather than aggregative approach to reviewing literature (Sandelowski et al, 2011; Gough et al, 2012).

The focus of the study was the education sector in England and Wales. However, the topic areas involved (knowledge adoption and evidence-informed policy making) have salience for, and have been studied within, other policy sectors and countries. As such, the screening criteria for the review were relatively 'broadly' framed: studies had to correspond to the topics of interest but could be either theoretical or empirical in nature. Studies were also required to be in English, and to relate to policy systems that had similarities to that of England and Wales (eg, Australia, Canada, the United States etc). Papers or studies relating to policy sectors other than education were included. Studies relating solely to evidence and practice were excluded.

Literature was initially searched for in two ways:

- A search was undertaken of four prominent databases (Academic Search Complete, IngentaConnect, JSTOR and Web of Knowledge) using search terms synonymous with that of 'knowledge adoption'. These included, for example: 'knowledge mobilisation', 'knowledge transfer' and 'knowledge exchange'; and were taken from the definitive list provided on the University of Toronto's Research Supporting Practice in Education website. ${ }^{1}$ 
- Recommendations on seminal literature were sought from (and provided by) colleagues, authors identified from the search above and experts in the fields of evidence-informed policy and knowledge adoption.

The references cited by the authors of these studies were then reviewed. Additional literature was also obtained where these references detailed papers that had not been picked up in the first two approaches, where these seemed pertinent to the research topic area. Overall, these three approaches to sourcing literature, combined with the screening criteria, resulted in a total of 228 studies being reviewed over a one-anda-half-year period. Further detail on the review may be found in Brown (2011).

\section{A description of existing models, derived from current literature}

From the literature review it has been possible to identify a number of models currently in existence, which seek to explain the process of knowledge adoption. The progression of these models illustrates how conceptions as to the drivers of adoption have evolved over time: Mitton et al (2007), for example, argue that the concept of 'knowledge transfer' dominated during the 1980s and 1990s. This led early explanations of adoption, for instance the Demand Pull Model (Weiss, 1979; Yin and Moore, 1988; Rich, 1991), to focus on one-way transfers or pushes of knowledge from researchers to policy makers (who had specifically requested the research). After its initial development, the notion of 'demand pull' was augmented by that of 'producer push' (Lavis et al, 2003), highlighting the growing perception that active efforts on the part of researchers were also required in order to inform decision making. Knowledge adoption thus also came to be viewed as a function of researcher engagement with potential audiences and how accessible research messages were made to these audiences (ie, the ways and means through which research is targeted at users).

The idea that pull and push alone could account for the adoption of knowledge was problematised, however, both by the conceptualisation of the Enlightenment Model (Weiss, 1998) and through the development of the Two Communities Model (Amara et al, 2004). Within the Enlightenment Model, for example, knowledge adoption was posited, not as a consequence of the findings of a single study or a body of knowledge, but from the percolation of evidence into the policy-making domain, causing policy makers to think differently about particular issues over a period of time. The Two Communities Model, meanwhile, assumed that a cultural gap exists between policy makers and practitioners on the one hand, and academic researchers on the other. As a consequence, the model advanced the notion that a lack of understanding exists between these 'two communities', leading to low levels of communication (and so knowledge adoption) between them. Mitton et al (2007) observe that, as a result of the issues raised by both the Enlightenment and Two Communities Models, later conceptualisations of knowledge adoption were grounded in the idea that the successful adoption of knowledge requires lengthy interaction rather than one-way conversation. Likewise, Nutley et al (2007) posit that the findings of research do not 'speak for themselves', they are interpreted and that this happens best through 
dialogue and engagement. As a result, models such as the Interaction/Communication and Feedback Model (Dunn, 1980; Yin and Moore, 1988; Nyden and Wiewel, 1992; Oh, 1997; Nutley et al, 2002; Amara, et al, 2004) and the Linkage and Exchange Model (Lavis et al, 2006) were developed to explain knowledge adoption as a dynamic, two-way process.

Other models, designed to complement those set out above, also spotlight specific aspects of the adoption process. For instance, the Organisational Interests Model (Amara et al, 2004) frames the argument that the size of organisations, their structures, the nature of their responsibilities and their needs may affect the propensity of professionals working within them to adopt and utilise research. Best and Holmes (2010) augment this analysis by suggesting that the 'organisational interests' that best account for how knowledge is turned into action comprise four interconnected factors: evidence and knowledge, leadership, networks and communications. The Engineering Model (Amara et al, 2004), meanwhile, suggests that the effective adoption of research depends on the characteristics of the research findings. These include content attributes (eg, compatibility, complexity, observability, trialability, validity, reliability, applicability etc) and the research type (eg, basic-theoretical/applied, general/abstract, quantitative/ qualitative, particular/concrete, and research domains and disciplines).

\section{A critique of current models}

These models have been subject to substantive critique, however. For example, the explanatory power of a number of them was tested empirically by Landry et al (2003) in a survey of 833 Canadian government officials. This empirical analysis led Landry et al to argue that the drivers of research adoption put forward by the Two Communities Model do seem to provide some indication as to whether knowledge will be adopted by policy makers. Likewise, the Interaction/Communication and Feedback Model seems to successfully explain some of the key drivers involved in research adoption. Landry et al suggest, however, that the determinants of research adoption, as postulated by the Organisational Interests Model, are mixed in terms of how well they predict whether research will be adopted successfully by policy makers and that factors postulated by the Engineering Model fail to effectively explain the processes involved in the successful adoption of research. As such, Landry et al conclude that while more interactive factors appear to best explain research adoption, overall the process is far more complex than these existing models might suggest. Estabrooks et al (2006: 26) too argue that there is currently no satisfactory overarching theory to explain effective research adoption, with most models tending to focus on 'explanation rather than prescription'. These sentiments echo the work of Wingens (1990), who describes the explanatory power of knowledge adoption models as 'mediocre', while Cooper et al (2009) argue that they are conceptually inadequate and fail to reflect the idea that knowledge use is a social process. Finally, Mitton et al (2007: 756) note that 'there is very little evidence that can adequately inform what [knowledge adoption] strategies work in what contexts'.

What emerges from this critique is that the knowledge adoption process is, as with other facets of the social world, incredibly complex in nature. As a result, that an 
underpinning conceptualisation of social action is required if any model of knowledge adoption is to be truly effective in terms of its explanatory power. This can be illustrated best by considering knowledge adoption as something directed towards a goal or purpose: the 'what' of knowledge adoption. In attempting to achieve this 'what', social actors will engage in empirically observable actions (the 'how' of knowledge adoption) and specific motivating factors will drive policy makers and researchers to engage in the actions they do (the 'why' of knowledge adoption). In applying this perspective to existing models, it is clear that they often account for the 'how' and the 'what', but invariably fail to consider the 'why'. For example, the Demand Pull Model describes its 'what' as the demand for evidence by policy makers in order to aid in problem solving. No explanation is provided, however, in terms of the reasons why researchers might be motivated to engage in this type of problem-solving behaviour (and conversely, why some are not). The Interaction/Communication and Feedback Model, on the other hand, posits that interaction encourages knowledge adoption. Interaction can be considered a 'how'; that is, it is something that can be observed and is geared towards a goal. Again, however, what is missing is an explanation for the reasons why policy makers or researchers may wish to interact with each other and so what might be driving the interactive process.

\section{Social activity method}

There is a myriad of social theories that have been developed to explain how the social world operates and functions. Knowledge adoption as social action can, however, be characterised by four pertinent features (Brown, 2011):

- As with any process of 'narration', knowledge adoption activity comprises story tellers and audiences.

- Both story tellers and audiences have distinctive roles and responsibilities in relation to the narration process.

- In keeping with Weiss' notion of 'enlightenment', adoption will be most successful if it occurs over long periods of time (ie, research 'stories' will tend to linger in the minds of policy makers if they have been repeatedly told and retold).

- Correspondingly, the end point of knowledge adoption must have been reached via one or more interaction(s) between policy makers and research/researchers, with each performing in a way specified by the requirements of their narrative role.

As a result, I argue that these characteristics correspond most closely with the sociological approach posited by Dowling $(2005,2007,2008 \mathrm{a}, 2008 \mathrm{~b})$ - the Social Activity Method.

The Social Activity Method was originally conceived by Dowling in 1993 and has been employed to analyse a myriad of social phenomenon and settings (see, for example, 2005, 2007, 2008b). Its central tenet is that all social action is centred on the relationships between social actors. This is set out most explicitly in Dowling's (2008b: 6) contention that 'the sociocultural is defined by autopoietic, ${ }^{2}$ strategic action that is directed towards the formation, maintenance and destabilising of alliances and 
oppositions and this interpretation can be applied at any level of analysis'. In other words, extant and nascent relationships (whether they be alliances or disunions) are always in the process of being built, maintained or destroyed; as such, strategies will constantly be being set in play by all concerned, in relation to such processes.

Through the lens of Social Activity Method, the successful adoption of knowledge can thus be taken to represent the result of a fruitful relationship, or alliance, between policy makers and researchers, with such an alliance comprising either a direct relationship between policy makers and academics or an indirect relationship between policy makers and the texts or work of researchers. As a result, knowledge adoption is most likely to occur when both researcher and policy maker are actively seeking to engage with one another, employing corresponding strategies to enable this process. Conversely, it will fail to materialise when one or more partners in the process do not put in place strategies directed towards making it happen. As a consequence, I argue, the Social Activity Method provides an effective way of conceptualising the aforementioned 'why' of knowledge adoption. In other words, it provides a plausible starting point for the motivating drivers for knowledge adoption-related activity. For example, why researchers might seek to respond to a demand pull or why interaction or interactive factors provide the best explanatory variables associated with knowledge adoption to date (Landry et al, 2003).

\section{Developing an alternative model: the 'policy preferences' approach}

Addressing the critique set out above requires more, however, than the simple insertion of the Social Activity Method into current models of knowledge adoption (which by itself will not tackle the issues set out by Landry et al - see above): it necessitates the development of a new model of knowledge adoption that has, as its starting position, the basic principles set out by the Social Activity Method.This development of such a model was undertaken in Brown (2011) and involved a thematic analysis of the literature identified above, which focused on identifying and grouping together the myriad of factors that affect the knowledge adoption process. The principal result of this analysis was the identification of two knowledge adoption motifs: the first encapsulates those factors that relate directly to the evidence to be adopted, and to attempts to communicate this evidence. The second comprises those factors that impact on how the findings from any given study are likely to be received by its audience. These themes are defined, respectively, as the internal and external knowledge adoption factors. The chief implications that arise from these themes are as follows:

- Researchers who are interested in informing policy are responsible, not only for managing their research approach and the interpretation of data, but also for strategies relating to the (internal) components that affect how they might attempt to communicate their findings to policy makers.

- Policy makers, as audiences, meanwhile, are responsible for how evidence is received: the factors that affect reception are external to any given study but still impact on whether its messages are taken on board. 
Set out below is a brief summary of these internal and external factors; more detail about each may be found in Brown (2011,2012a). To begin with, the internal factors affecting knowledge adoption are:

- the nature of what is being communicated (Lindblom and Cohen, 1979; Kirst, 2000; Lavis et al, 2003; Davies, 2006; Campbell et al, 2007; Moore et al, 2011) - that is, the notion that policy makers are keen to receive 'straightforward' narratives or stories coupled with advice they can understand;

- clarity with regards to its presentation - this refers to the idea that "presentation is key: research must be attractive ... and visually appealing' (Nutley et al, 2007: 71);

- the efficacy of the communication type - analyses by Cohn (2006), Davies (2006) and Levin (2008) all indicate that passive communication processes (eg, making research findings available via websites) are ineffective, while interactive faceto-face engagements between policy makers and researchers are more likely to lead to research findings being acted upon;

- the level of proactivity, contextualisation and tailoring - Levin (2004) argues that policy makers should be provided with the full range of evidence-informed options for policies. As a result, research findings should be contextualised by and shown to relate to other 'ball-park' evidence. Lavis et al (2003) meanwhile link contextualisation to the tailoring of content and conclude that all audiences for a particular piece of evidence must be well defined and understood in advance of any communication.

The external factors comprise:

- factors inherent to policy makers and which constitute their knowledge 'mould' (Huberman, 1990; Levin, 2004) - that is, the idea that it is in the gift of policy makers as to which information they digest, or whether they choose to re-examine longstanding viewpoints;

- the perceived credibility of the source of evidence by policy makers, itself a function of the reputations of those providing the research (Kirst, 2000; Court and Young, 2003; Landry et al, 2003; Campbell et al, 2007; Nutley et al, 2007);

- the perceived quality of the evidence by policy makers, with both Campbell et al (2007) and Nutley et al (2007) suggesting that policy makers' perceptions as to the quality of a study will also affect any demand for evidence;

- general involvement by policy makers in research studies - the Council for Science and Technology (2008), Moore et al (2011) and Rickinson et al (2011) note that user engagement is crucial to maintaining dialogue and the continuous flow of ideas, ensuring that projects remain relevant and at the forefront of policy makers' thinking;

- access to policy makers - the notion that, in the absence of the active involvement of policy makers in research projects, researchers must find alternative ways for their messages and outputs to reach them (see, for example, Sylva et al, 2007). 
In addition to the internal and external factors set out above, a secondary thematic grouping also emerged from the analysis, highlighting two factors that stem from the preferences of policy makers (the 'policy preference' factors). The first policy preference factor indentified is concerned with whether the research relates to an idea currently favoured by policy makers (Gladwell, 2000; Kirst, 2000; Landry et al, 2003; Cohn, 2006; Levin, 2008). This is because if a study is situated within, or contributes towards, a concept that policy makers are interested in enshrining as policy, then there is more chance that it will be adopted by them than if it does not (eg, if the study relates to a subject that is lacking in social relevance).

The second policy preference factor addresses any extant interplay between policy makers and researchers: for example, the term 'privileged' researcher was introduced in Brown (2011) to describe any knowledge producer who can quickly and easily access policy makers (because they either work with or are favoured by them) and so encompasses a range of policy actors. For instance, government or 'insider' researchers (Brown, 2009) or (previously privileged before 2010) those identified by Ball (2008: 104 ) as the 'intellectuals of New Labour'. As a result, this second policy preference factor is described as the strength and nature of the relationship between researchers and policy makers, recognising that this changes over time (Stronach and MacLure, 1997; Rich, 2005; Cohn, 2006; Davies, 2006; Ball, 2008; Ball and Exley, 2010; Exley, 2008). Thus, researchers with strong, possibly ideologically related, ties to policy makers may have certain perceived organisational or sector-level salience and so more chance of gaining access to and having their research considered by policy makers, than those who do not. While related to a number of the external factors above, this policy preference factor can be, and is, differentiated from them. In part this is due to the myriad of relationships it is possible for researchers to have with policy makers: for instance, a researcher may simply be a provider of a contracted piece of research, won via a tendering process; alternatively, they may be a trusted adviser and ideological advocate or openly sympathetic to the government; they may even be the friend of the policy maker concerned.Thus, a researcher may be credible and respected (a vital external factor) but may not have a carte blanche to discuss all and any policy ideas with policy makers (or vice versa). Likewise, there may be in place project-related structures that enable researchers to access policy makers with regards to specific findings, but on other topics or areas of research, these same researchers may not have recourse to approach policy makers directly or have their findings treated in the same way.

\section{A new model of research adoption}

Having identified these themes and their component factors, they were then combined so that they might effectively explain the knowledge adoption process, while simultaneously tackling the critique of previous models. In keeping with Dowling's $(2005,2007,2008 \mathrm{a}, 2008 \mathrm{~b})$ approach, the model's fundamentals were based in relationship-related activity, with the successful adoption of knowledge interpreted as something that requires partnership working between researchers and policy makers, with each being required to play their part in negotiating the internal/ external factors set out above. At the same time, the two policy preference factors provide the 
context for the enactment of knowledge adoption in its totality: that is, the idea to which the research pertains is either favoured or it is not and the researcher either has strong ties with policy makers or they do not. These four binary options (idea is/not in favour and researcher is/not in favour) thus provide four 'ideal-type' knowledge adoption scenarios. The ease with which knowledge adoption-related relationships might be established within each, will be dependent on who is communicating the research, and their ties to policy makers, and whether a study does or does not relate to an idea currently in favour with policy makers.

Correspondingly, the complexity of the knowledge adoption process will vary with each of these four scenarios: this complexity is expressed by differentiating, within each scenario, between those internal and external factors that may be considered crucial to the process and those that are less important. For example, it has been shown that policy makers are most likely to be receptive to research where the underpinning idea is in favour. The crucial factors for a researcher with strong relationships with policy makers to consider (develop strategies to account for) in disseminating such research, therefore, are those internal factors associated with its effective communication; the other knowledge adoption factors detailed above, while relevant, are less important because they have been pre-negotiated or dealt with by dint of the researcher/ research's position vis-à-vis the policy preference factors (this is set out in Figure 1 as Scenario 1). The diametrically opposite position (Scenario 4) is considered to be where a researcher with a weak relationship with policy makers is attempting to disseminate knowledge to policy makers where the underpinning research does not relate to ideas currently in favour. Here, as well as the internal factors associated with effective communication, the researcher also has to consider (and develop strategies to account for) relevant external factors controlled by policy makers:

- how to situate evidence in order to create a demand for it;

- how the perceived credibility of the source can be maximised;

- whether the audience has been engaged in policy networks or other forms of user engagement;

- how to demonstrate or account for the quality of the evidence;

- how to gain access to policy makers.

As a result, it is argued that the process of researchers with strong ties to policy makers and disseminating favoured research to them, may be considered far less difficult than processes associated with a weakly connected researcher attempting to inject unfavoured ideas into the policy-making process.

The same is true for policy makers, in particular government researchers who mediate between academic researchers and policy makers (Brown, 2009): when looking to adopt socially robust knowledge from strongly connected academic researchers, policy makers will have to set out their stall in terms of indicating the most effective ways or media through which it is best to communicate evidence. They should also be open to concepts such as 'proactivity' and to work with researchers to help them to understand the essential features of clear and accessible messages. For policy makers to be effective audiences for new thought and to successfully 
engage with weakly connected academic researchers, they will, in addition, need to think about how such researchers are generally able to access both themselves and their institutions or departments. They might also consider and remove (or help researchers to negotiate) any hurdles that have been put in place unnecessarily with regard to the quality of studies or credibility of the source. Finally, they must respond positively to invitations to join networks or to partake in user engagement processes and programmes. In all cases, ultimately policy makers need to ensure that suitable mechanisms, infrastructure and types of culture or behaviour exist within government departments and agencies so that evidence is considered throughout the policy-making process. In addition, intermediate positions also exist: these scenarios and strategies are set out in full in Figure 1.

\section{Figure I:The 'policy preferences' approach to knowledge adoption}

\begin{tabular}{|c|c|c|}
\hline & $\begin{array}{l}\text { Idea currently favoured by UK policy } \\
\text { makers }\end{array}$ & $\begin{array}{l}\text { Idea not in favour with UK policy } \\
\text { makers }\end{array}$ \\
\hline $\begin{array}{l}\text { Communicated by } \\
\text { those with strong } \\
\text { relationships with } \\
\text { policy makers }\end{array}$ & $\begin{array}{l}\text { Scenario I } \\
4 \text { crucial factors: } \\
\text { most effective media; nature of the } \\
\text { message; clarity of presentation; } \\
\text { proactivity, context and tailoring } \\
5 \text { less important ones: } \\
\text { creating demand for research; } \\
\text { credibility of the source; user } \\
\text { engagement?; quality of evidence; } \\
\text { access to policy makers }\end{array}$ & $\begin{array}{l}\text { Scenario } 2 \\
7 \text { crucial factors: } \\
\text { most effective media; nature of the } \\
\text { message; clarity of presentation; } \\
\text { proactivity, context and tailoring; } \\
\text { creating demand for research; user } \\
\text { engagement?; quality of evidence } \\
2 \text { less important ones: } \\
\text { credibility of the source; access to } \\
\text { policy makers }\end{array}$ \\
\hline $\begin{array}{l}\text { Communicated by } \\
\text { those with weak } \\
\text { relationships with } \\
\text { policy makers }\end{array}$ & $\begin{array}{l}\text { Scenario } 3 \\
8 \text { crucial factors: } \\
\text { most effective media; nature of the } \\
\text { message; clarity of presentation; } \\
\text { proactivity, context and tailoring; user } \\
\text { engagement?; quality of evidence; } \\
\text { credibility of the source; access to } \\
\text { policy makers }\end{array}$ & $\begin{array}{l}\text { Scenario } 4 \\
9 \text { crucial factors: } \\
\text { most effective media; nature of the } \\
\text { message; clarity of presentation; } \\
\text { proactivity, context and tailoring; } \\
\text { creating demand for research; } \\
\text { credibility of the source; user } \\
\text { engagement?; quality of evidence; } \\
\text { access to policy makers }\end{array}$ \\
\hline
\end{tabular}

It is argued that the model set out in Figure 1 significantly improves on the way in which the knowledge adoption process is currently conceived. For example, combining the notion that knowledge adoption is dependent on researchers and policy makers seeking to form relationships, with the idea that the effective adoption of research is a function of factors that are internal, external and policy preference, provides the 'why' that, up until now, has been missing; whereas existing models, such as Demand Pull, represent knowledge as something adopted $\backslash$ transferred $\backslash$ exchanged through chains or flows and via mechanics, and it can be claimed that this type of representation is 
concerned solely with process. The model illustrated in Figure 1, on the other hand, represents a different conceptualisation: that knowledge flows can only come into being if policy makers and researchers are motivated to form a relationship with one another and, simultaneously, that their actions must be directed towards achieving knowledge adoption/overcoming barriers to achieving the adoption of knowledge as an end goal.

The 'how' of knowledge adoption is also further developed: in representing knowledge adoption as a function of both internal and external factors, the model illustrates the hurdles that researchers will need to develop successful strategies to negotiate if they are to communicate effectively or disseminate evidence to policy makers. This is also the case for policy makers attempting to act as effective audiences for research outputs.

At the same time, Figure 1 illustrates, should they wish to develop policy without being encumbered with what might be viewed as inconvenient research messages, the ways through which policy makers can seek to undermine any value that research evidence might provide. For example, interview data in Brown (2011) revealed that policy makers often promote a 'deficit' model of research; that is, the view that it is researchers alone who are responsible for the failure of any actualisation of evidenceinformed policy (Perry et al, 2010). This then means that policy makers can target factors such as the 'quality of the evidence', the 'clarity of presentation', the 'nature of the message' etc as specific reasons for not taking on board the findings of a given study.

In utilising the two policy preference factors, Figure 1 also illustrates how the actual communicator of the research and, correspondingly, their position with regard to policy makers has as much a role to play in determining whether knowledge adoption will occur, as the nature of the research (ie, whether it relates to an idea currently favoured by policy makers). As such, unlike past models of knowledge adoption, the model highlights the differences in complexity that accrue depending on the situation at hand, rather than assuming equality in all situations. Similarly, while the model is based on the premise that knowledge adoption is relationship dependent and, as such, occurs at the level of the individual project/researcher/policy maker (ie, it is individuals not organisations who adopt or produce research findings), at the same time, the policy preference factors that come together to form Figure 1 should be regarded as representing an element of discursive control on the part of policy makers, since they may both be considered policy maker-centric. In other words, they ask whether policy makers, rather than researchers, perceive knowledge to be 'in favour', while also looking at who it is that policy makers' privilege. As such, these factors provide an acknowledgement that the complexity of the situation affecting the knowledge adoption process will be determined at a macro level (eg, discursive control tends to operate at the level of groups or organisations, not individuals: see Foucault, 1978, 1980; Ball, 2008) and that knowledge adoption takes place within a discursive paradigm rather than being immune to outside influences. 


\section{Methodology: use of in-depth, semi-structured interviews to further develop the knowledge adoption model}

Because the model was developed through reviewing literature, rather than any empirical engagement, there was a requirement to establish its validity with those involved in knowledge adoption activity. In order to test and further develop the model, 24 in-depth, semi-structured interviews were undertaken subsequently with policy makers and researchers. In particular, these were designed to establish the face validity of the model (ie, did it appear successfully to explain the knowledge adoption process?) and to establish the model's conceptual gaps (ie, how could the model be improved?). Those classed as policy makers were either politicians (current or exministers) or civil servants in central government. Researcher respondents comprised those working for higher education institutes or think tanks. While a purposeful sample of what Brown and Dowling (1998) term 'critical cases' was selected (ie, a sample of individuals whose characteristics meant that they corresponded directly to the analytical requirements of the project), care was taken to include both advocates (those who believe that evidence can and should be used to inform policy/those responsible for knowledge adoption activity) and critics (those who regard the concept of 'evidence-based policy' as undesirable/unfeasible). This provided a wide range of views and opinions from which to draw upon and assess. It also provided a rigorous critique of the study and its resultant conceptual/theoretical development. The distribution of the final participants is presented in Table 1 (note that the number adds to more than the total number of people interviewed as the groups were not mutually exclusive).

Table I: Distribution of interview participants

\begin{tabular}{|c|c|}
\hline Group/viewpoint & Number \\
\hline Politicians based in England and Wales & 2 \\
\hline Civil servants based in England and Wales & 4 \\
\hline $\begin{array}{l}\text { Researchers considered from the literature, or self-identified, as favoured by } \\
\text { politicians or civil servants }\end{array}$ & 9 \\
\hline $\begin{array}{l}\text { Researchers considered from the literature, or self-identified, as less favoured } \\
\text { by politicians or civil servants }\end{array}$ & 6 \\
\hline Academic researchers critical of the concept of 'evidence-informed policy' & 4 \\
\hline Academic researchers in favour of evidence-informed policy & II \\
\hline $\begin{array}{l}\text { Respondents belonging to think tanks, political advisers or those operating at } \\
\text { the higher levels of Davies' (2006) policy-making 'food chain' }\end{array}$ & 3 \\
\hline
\end{tabular}

Following the interviews, abductive thematic analysis was employed to identify incipient thought relating to the model and its operation. Mason (2002: 180) defines 'abductive' analysis as a process through which 'theory, data generation and data analysis are developed simultaneously in a dialectical [fashion]'. Mason's (2002) approach thus accounts for the way in which themes and codes were derived from the interview data and how they enabled the augmentation of extant literature. 
Simultaneously, the validity of the findings was established: in particular, Lincoln and Gubba's (1985) technique of 'member-checking' was adopted, which ensured that the study's interpretations and conclusions were thoroughly tested with those who participated. In addition, interpretive rigour was also achieved through the use of verbatim quotations - an approach that accords with the request made by Fereday and Muir-Cochrane (2006) for transparent 'illustration'. It is argued that both the positive responses received from respondents after assessing the study's findings, combined with the direct reflections of the participants in the reporting of the analysis, add a further level of face validity to the analysis presented below.

\section{Analysis of the interview data}

Analysing the interview data enabled the face validity of Figure 1 to be assessed in a number of ways - first through respondents' comments. For example, it was agreed that the adoption of knowledge is a two-way interaction and as one academic researcher noted: "everybody should take responsibility for their part in the process" (academic \#11). The pivotal importance of each policy preference factor was also confirmed: in discussing the importance of the policy preference factors, one policy maker noted, "you want people of prestige and reputation" (civil servant \#6). One think-tank interviewee also argued that "[y]ou're judged by the quality of your previous work: if you've had the good ideas in the past then people are going to come to you in the future" (consultancy/think tank \#1).

Academics, too, affirmed that the reputation of a knowledge provider and the regard in which they are held, positively affects how policy makers receive their work. As a result, if one is considered reputable, the process of knowledge adoption becomes simpler. For instance:

'People are interested in hearing what I've got to say for two reasons: one - over a period of time I've generated a reputation for knowing a lot and being at the forefront of thinking about education ...; and two - I think this is important for policy makers, I've actually been there and done it.... So those two things plus my writing knowledge do mean that education ministers or Prime Ministers are interested to speak to me, so yes absolutely.' (Academic \#2)

All respondents also intimated, as suggested by the model, that the factors that need to be negotiated by researchers with strong ties to policy makers are fewer and less complex than those that need to be overcome by those who do not: "I suppose it's the same in any walk of life ... you find somebody that you feel is aligned with you and you trust them and therefore you don't need chapter and verse" (academic \#3), again reflecting findings from the initial literature review that 'privileged' or strongly tied researchers have more chance of influencing (or have less barriers to overcome in their attempts at influencing) policy makers than those who are not. Interview data also lent weight to the notion that the level of favour afforded to the evidence in question is vital to such knowledge being adopted. As one academic noted: "The 
topic has got to be pertinent ... something that's very esoteric is unlikely to engage policy makers unless they are very, very unusual" (academic \#10).

At the same time, however, the policy preference factors that come together to form Figure 1 allude to the notion that some of those seeking to influence policy will be in more powerful positions than others and that such power differentials affect the nature of any relationship. As one academic noted: "I think all this business about being a trusted adviser is actually quite important...." (academic \#3). In this sense, the policy preferences approach also provides a distinct perspective in that it introduces notions of power that, hitherto, have been neglected.

Finally, in Brown (2012a), the existence of strategies designed to negotiate the policy preference, internal and external factors that form Figure 1 is also identified. As a result, it is contended that knowledge adoption can be facilitated by the employment of one, all or any combination of four approaches. These have been described as:

- academics providing outputs that attempt to meet policy makers' and politicians' specific requirements from research ('policy-ready' strategies);

- researchers seeking to effectively communicate and/or use effective techniques or channels to promote their research ('promotional' strategies);

- academics engaging in 'traditional' academic behaviour ('traditional' strategies);

- academics attempting to shift their relative position with regard to how 'privileged' they are regarded by policy makers (which affects the ease with which they can access or influence them), or how policy makers perceive the policy context to which their research pertains ('contextual'strategies).

What is more, the use of different combinations of these strategies by respondents also indicates that knowledge adoption can be regarded as a contextually specific social process; respondents suggested and also behaved in ways to indicate that different approaches to knowledge adoption are required in different circumstances. For example, this is illustrated in Brown (2011)), where I compared the knowledge adoption strategies employed by Barber and Mourshed (2007) in the production of their study on how the world's best-performing school systems come out on top, to those used by Sylva et al (2007) in promoting the Effective Pre-School and Primary Education 3-11 longitudinal study. Overall, then, not only did Figure 1 ring true with interviewees (ie, it had face validity), but respondents also behaved in ways that suggest that its description of how knowledge adoption might operate is representative of the social world more generally.

\section{Conclusions}

The process of knowledge adoption and its efficacy should be considered essential precursors to the development of evidence-informed policy. Understanding adoption as a process - how it operates and how efforts in this area can be improved - is vital, both for researchers wishing to influence policy and for policy makers seeking to improve the efficacy, effectiveness and equitability of their policies (Oxman et al, 2009). Within this paper it is argued that existing models of knowledge adoption

Evidence \& Policy $\bullet$ vol $8 \cdot$ no $4 \cdot 2012 \cdot 455-72 \cdot$ http://dx.doi.org/I 0.1332/I744264I IX660 I06 
fail to capture fully the complexities and social nature of the knowledge adoption process. This has led to the design of a new way of thinking about knowledge adoption (through engaging with relevant and recent literature) and testing this new model among educational policy makers and researchers in England and Wales.

While the empirical aspect of the work indicates that respondents both agreed that the model represents their experiences of knowledge adoption, they also behaved in ways to suggest that this was indeed the case, specifically by developing strategies designed to negotiate the internal, external and policy preference factors that come together to form Figure 1. As a result, it is argued that the interview data indicate that the approach is valid and has explanatory power. At the same time, however, further research is needed to ascertain the model's predictive power, for example by employing a similar approach to that of Landry et al (2003), who surveyed some 833 Canadian government officials about their research adoption behaviours, used regression analysis to ascertain corresponding determinants of research adoption and then sought to match these to those predicted by current theoretical models.

I also argue that, as it stands, this new model represents a clear and distinctive perspective from that provided by existing frameworks. In doing so it can be argued that the model meets the requirements set out by Cooper and Levin (2010: 15), who request that conceptualisations of research use "move past formulations such as "research use is complex and multifaceted", to describe that complexity and its component elements so that these can be analyzed and assessed'. Consequently, the model may be seen to move current understandings of research adoption to a point where 'we can design and implement more effective interventions that target the areas that have the greatest potential to improve systems' (Cooper and Levin, 2010: 15). It is suggested that this model has salience both for academic researchers seeking to inform policy and also for mediators whose role it is to broker knowledge between researchers and policy makers (see, for example, Sin, 2008). For instance, government researchers may find it useful to employ such a model and use it to guard their policymaking colleagues against fashion: that is, to make it easier for researchers whose ideas are not currently favoured but which may impact positively on policy to bring these to the attention of policy makers.

\section{Notes}

${ }^{1}$ See www.oise.utoronto.ca/rspe/KM_Products/Terminology/index.html

${ }^{2}$ Dowling (2005) uses the term 'autopoietic' to mean a system that is self-creating/selforganising.

\section{References}

Amara, N., Ouimet, M. and Landry, R. (2004) 'New evidence on instrumental, conceptual, and symbolic utilization of university research in government agencies', Science Communication, 26(1): 75-106.

Ball, S. (2008) The education debate, Bristol:The Policy Press. 
Ball, S. and Exley, S. (2010) 'Making policy with "good ideas": policy networks and the "intellectuals" of New Labour', Journal of Education Policy, 25 (2): 151-69.

Barber, M. and Mourshed, M. (2007) How the world's best-performing school systems come out on top, London: McKinsey \& Co, http://mckinseyonsociety.com/how-the-worldsbest-performing-schools-come-out-on-top/

Best, A. and Holmes, B. (2010) 'Systems thinking, knowledge and action: towards better models and methods', Evidence \& Policy, 6 (2): 145-59.

Brown, A. and Dowling, P. (1998) Doing research/reading research: A mode of interrogation for education, London: Falmer Press.

Brown, C. (2009) 'Effective research communication and its role in the development of evidence-based policy making: a case study of the Training and Development Agency for Schools', MRes dissertation, Institute of Education, University of London.

Brown, C. (2011) 'What factors affect the adoption of research within educational policy making? How might a better understanding of these factors improve research adoption and aid the development of policy?', DPhil dissertation, University of Sussex.

Brown, C. (2012a) 'Exploring the concepts of knowledge adoption and conceptual impact: implications for educational research submissions to the Research Excellence Framework (2014)', Evidence, Knowledge and Economy Journal, 5 (3): 137-54.

Brown, C. (2012b) 'The policy agora: how the epistemological and ideological preferences of policy-makers affect the development of government policy', Human Welfare, 1 (1): $57-70$.

Campbell, S., Benita, S., Coates, E., Davies, P. and Penn, G. (2007) Analysis for policy: Evidence-based policy in practice, London: HM Treasury.

Cohn, D. (2006) 'Jumping into the political fray: academics and policy making', IRPP Policy Matters, 7 (3): 1-31.

Cooper, A. and Levin, B. (2010) 'Some Canadian contributions to understanding knowledge mobilization', Evidence \& Policy, 6 (3): 351-69.

Cooper, A., Levin, B. and Campbell, C. (2009) 'The growing (but still limited) importance of evidence in education policy and practice', Journal of Educational Change, 10 (2-3): 159-71.

Council for Science and Technology (2008) How academia and government can work together, London: Department of Innovation, Universities and Skills.

Court,J. andYoung,T. (2003) Bridging research and policy: Insights from 50 case studies, London: Overseas Development Institute.

Davies, P. (2006) 'Scoping the challenge: a systems approach', Paper presented to the National Forum on Knowledge Transfer and Exchange, Toronto, Canada, 23-24 October, www.chsrf.ca/other_documents/event_reports/pdf/philip_davies.ppt.pdf

Dowling, P. (2005) Treacherous departures, http://homepage.mac.com/paulcdowling/ioe/ publications/dowling2005/TreacherousDepartures.pdf

Dowling, P. (2007) Organizing the social, http://homepage.mac.com/paulcdowling/ioe/ publications/dowling2007.pdf

Dowling, P. (2008a) 'Unit 4: Generating a research question,' in Research and the theoretical field lecture pack and reading pack, London: University of London.

Dowling, P. (2008b) Mathematics, myth and method: The problem of alliteration, http:// homepage.mac.com/paulcdowling/ioe/publications/dowling2008a.pdf 
Dowling, P. (1993) A language for the sociological description of pedagogic texts with particular reference to secondary school mathematics scheme SMP 11-16, PhD thesis, London: University of London.

Dunn,W. (1980) 'The two communities metaphor and models of knowledge us', Knowledge: Creation, Diffusion, Utilization, 1: 515-36.

Estabrooks, C., Thompson, D., Lovely, J. and Hofmeyer, A. (2006) 'A guide to knowledge translation theory', Journal of Continuing Education in the Health Professions, 26: 25-36.

Exley, S. (2008) The politics of specialist school policy making in England, London: University of London.

Fereday, J. and Muir-Cochrane, E. (2006) 'Demonstrating rigor using thematic analysis: a hybrid approach of inductive and deductive coding and theme development', International Journal of Qualitative Methods, 5 (1): 1-11.

Foucault, M. (1978) The history of sexuality:Vol 1:An introduction, Harmondsworth:Penguin.

Foucault, M. (1980) Power/knowledge: Selected interviews and other writings, 1972-1977, New York, NY: Pantheon.

Gladwell, M. (2000) The tipping point: How little things can make a big difference, London: Little Brown.

Gough, D., Oliver, S. and Thomas, J. (eds) (2012) An introduction to systematic reviews, London: Sage Publications.

Huberman, M. (1990) 'Linkage between researchers and practitioners: a qualitative study', American Educational Research Journal, 27 (2): 363-91.

Kirst, M. (2000) 'Bridging education research and education policymaking', Oxford Review of Education, 26 (3-4): 379-91.

Landry, R.,Amara, N. and Lamari, M. (2003) 'The extent and determinants of utilization of university research in government agencies', Public Administration Review, 63 (2): 192-205.

Lavis, J., Lomas, J., Hamid, M. and Sewankambo, N. (2006) 'Assessing country-level efforts to link research to action', Bulletin of the World Health Organization, 84: 620-8.

Lavis, J., Robertson, D., Woodside, J., McLeod, C. and Abelson, J. (2003) 'How can research organizations more effectively transfer research knowledge to decision makers', The Milbank Quarterly, 81 (2): 221-48.

Levin, B. (2004) 'Making research matter more', Education Policy Analysis Archives, 12 (56): 1-20.

Levin, B. (2008) 'Thinking about knowledge mobilization', Paper prepared for an invitational symposium sponsored by the Canadian Council on Learning and the Social Sciences and Humanities Research Council of Canada, 15-18 May.

Lincoln,Y. and Guba, E. (1985) Naturalistic inquiry, Newbury Park, CA: Sage Publications.

Lindblom, C. and Cohen, D. (1979) Usable knowledge: Social science and social problem solving, New Haven, CT:Yale University Press.

Mason, J. (2002) Qualitative researching, London: Sage Publications.

Mitton, C., Adair, C., McKenzie, E., Patten, S. and Waye Perry, B. (2007) 'Knowledge transfer and exchange: review and synthesis of the literature', The Milbank Quarterly, 85 (4): 729-68.

Moore, G., Redman, S., Haines, M. and Todd, A. (2011) 'What works to increase the use of research in population health policy and programmes: a review', Evidence \& Policy, 7 (3): 277-305. 
Nutley, S.M., Davies, H.T.O. and Walter, I. (2002) Learning from the diffusion of innovations, Edinburgh: Research Unit for Research Utilisation, University of St Andrews.

Nutley, S.M., Walter, I. and Davies, H.T.O. (2007) Using evidence: How research can inform public services, Bristol: The Policy Press.

Nyden, P. and Wiewel,W. (1992) 'Collaborative research: harnessing the tensions between researchers and practitioners', The American Sociologist, 23 (4): 43-5.

Oh, C. (1997) 'Explaining the impact of policy information on policy-making', Knowledge and Policy, 10 (3): 25-55.

Oxman, A., Lavis, J., Lewin, S. and Fretheim, A. (2009) 'SUPPORT Tools for evidenceinformed health Policymaking (STP) 1: what is evidence-informed policymaking?', Health Research Policy and Systems, 7 (suppl 1): S1, www.health-policy-systems.com/ content/7/S1/S1

Perry, A., Amadeo, C., Fletcher, M. and Walker, E. (2010) Instinct or reason: How education policy is made and how we might make it better, Reading: CfBT Education Trust.

Rich,A. (2005) Think tanks, public policy and the politics of expertise, Cambridge: Cambridge University Press.

Rich, R. (1991) 'Knowledge creation, dissemination, and utilization', Knowledge: The International Journal of Knowledge Transfer and Utilization, 12 (3): 319-37.

Rickinson, M., Sebba, J. and Edwards, A. (2011) Improving research through user engagement, London: Routledge.

Sandelowski, M.,Voils, C., Leeman,J. and Crandell,J. (2011) 'Mapping the mixed methodsmixed research synthesis terrain', Journal of Mixed Methods Research, https://portal.ioe. ac.uk/http/mmr.sagepub.com/content/early/recent

Sin, C. (2008) 'The role of intermediaries in getting evidence into policy and practice: some useful lessons from examining consultancy-client relationships', Evidence $\&$ Policy, 4 (1): 85-103.

Stronach, I. and MacLure, M. (1997) Educational research undone: The postmodern embrace, Buckingham: Open University Press.

Sylva, K., Taggart, B., Melhuish, E., Sammons, P. and Siraj-Blatchford, I. (2007) ‘Changing models of research to inform educational policy', Research Papers in Education, 22 (2): 155-68.

Weiss, C. (1979) 'The many meanings of research utilisation', Public Administration Review, 29: 426-31.

Weiss, C. (1998) 'Have we learnt anything new about the use of evaluation?', American Journal of Evaluation, 19 (1): 12-13.

Wingens, M. (1990) 'Toward a general utilization theory: a systems theory reformulation of the two-communities metaphor', Knowledge, 12 (1): 27-42.

Yin, R.K. and Moore, G.B. (1988) 'Lessons on the utilisation of research from nine case study experiences in the natural hazards field', Knowledge in Society, 1 (3): 25-44.

\section{Chris Brown}

Institute of Education, University of London, UK christopher.brown@mac.com 